\title{
Bovine rabies in Turkey: patterns of infection and implications for costs and control
}

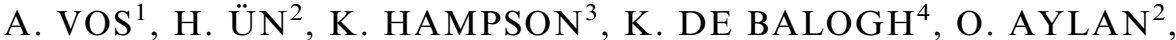 \\ C. M. FREULING ${ }^{5}$, T. MÜLLER ${ }^{5}$, A. R. FOOKS $S^{6,7}$ AND N. JOHNSON ${ }^{6 *}$ \\ ${ }^{1}$ IDT Biologika GmbH, Am Pharmapark, Dessau-Rosslau, Germany \\ ${ }^{2}$ Etlik Veterinary Control Central Research Institute (EVCCRI), Etlik-Ankara, Turkey \\ ${ }^{3}$ Boyd Orr Centre for Ecosystem \& Population Health, BAHCM, MVLS, University of Glasgow, Glasgow, UK \\ ${ }^{4}$ Food and Agriculture Organization of the United Nations, Viale delle Terme di Caracalla, Rome, Italy \\ ${ }^{5}$ Friedrich Loeffler Institut (FLI), Institute of Molecular Biology, Reims, Germany \\ ${ }^{6}$ Animal Health and Veterinary Laboratories Agency, Wildlife Zoonoses and Vector-borne Diseases Research \\ Group, Department of Virology, Surrey, UK \\ ${ }^{7}$ University of Liverpool, Department of Clinical Infection, Microbiology and Immunology, Liverpool, UK
}

Received 27 June 2013; Final revision 3 October 2013; Accepted 15 October 2013;

first published online 26 November 2013

\section{SUMMARY}

The incidence of rabies in livestock is an important factor for estimating the economic impact of the disease, but obtaining reliable data is hindered by inadequate surveillance. In order to understand the contribution of livestock rabies to the overall burden of disease, the rabies incidence in cattle was investigated in detail for Turkey between 2008 and 2011. Data were compiled on cattle numbers, samples submitted for rabies diagnosis, vaccinated animals and positive rabies cases in animals for seven regions in Turkey. Rabies incidence in cattle fluctuated annually and differed between regions from $0 \cdot 10$ to $3 \cdot 87$ cases $/ 100000$ animals. The positive influence of compensation schemes was observed. Livestock losses were conservatively estimated at around $\$ 250000$ international dollars per annum, although in areas where compensation schemes are not operating this could be an underestimate of the economic burden. Vaccination of cattle remains an option for disease prevention, although oral rabies vaccination through aerially distributed baits should be implemented to prevent the further spread of fox-mediated rabies, which could result in much greater economic costs.

Key words: Cattle, rabies, surveillance, Turkey, wildlife.

\section{INTRODUCTION}

Rabies is caused by viruses belonging to the genus Lyssaviruses, within the family Rhabdoviridae. The disease is found throughout the world and is transmitted by bats and carnivore species, especially canids [1]. All mammals are susceptible to infection with

\footnotetext{
* Author for correspondence: Dr N. Johnson, Animal Health and Veterinary Laboratories Agency, Woodham Lane, Surrey, UK. (Email: Nick.Johnson@ahvla.gsi.gov.uk)
}

these viruses. Livestock, such as cattle, goats, sheep and horses are dead-end hosts for rabies and as herbivorous animals are not well adapted to onward transmission of the disease. However, infected animals need to be humanely destroyed and prevented from entering the food chain to avoid human contact during carcass preparation. Costs arise through veterinary destruction of such animals, diagnostic testing, vaccination of at-risk animals and replacement of affected livestock. Livestock typically become infected by rabies virus after being bitten by reservoir hosts, 
such as domestic dogs (Canis lupus familiaris), the red fox (Vulpes vulpes), or in Latin America, by vampire bats (Desmodus rotundus). Therefore patterns of infection in livestock depend upon the infection dynamics of disease reservoirs within a particular area and opportunities for contact between livestock and reservoir populations [2]. However, this is a poorly studied or reported occurrence when the impact of rabies infection is considered, with a limited number of anecdotal reports of disease in cattle [3-5] and other livestock [6].

Although great progress has been made in rabies prevention and control, especially in the developed world, the burden of rabies on public and animal health in developing countries remains considerable. Estimates of the burden of rabies have been based on probabilistic modelling techniques, because of a lack of reliable data on disease incidence [7]. This is true for both the human cost of disease and the economic impact due to factors such as the implementation of post-exposure prophylaxis for human populations, disease control measures and direct losses of livestock due to transmission from local reservoirs of infection. Since rabies is invariably fatal, resulting livestock losses are a major economic problem, but there is a particular shortage of published estimates of rabies incidence in livestock and the resulting economic cost. The few published reports of bovine rabies in African and Asian countries, where the main source of disease transmission is the domestic dog, demonstrate that livestock losses from spillover can be substantial [8-10]. In many parts of the world, people rely on livestock for food and for work, and therefore bovine rabies can potentially have a significant impact on livelihoods.

To assess the societal costs of rabies, including the economic impact, reliable data on disease incidence in livestock is of utmost importance. Unfortunately, widespread underreporting of rabies in developing countries, including cases in livestock, is a major obstacle to understanding the true impact of the disease. It also inhibits the subsequent development of appropriate prevention methods, both for prophylactic measures in livestock and to control the disease in reservoir hosts. To address this issue, this study analysed bovine rabies data for Turkey, a country with both dog- and fox-mediated rabies [11] and an established rabies surveillance system [12]. We examined patterns of infection in cattle and how these related to cases in domestic dogs and foxes, respectively, with the aim of elucidating patterns of circulation in reservoir hosts and spillover into livestock. In addition, data on the number and density of cattle has been compiled to calculate the incidence of rabies in cattle on a regional and countrywide basis. Rabies is endemic throughout Turkey, where livestock management includes agropastoralism and pastoralism, smallholdings and large-scale intensive farming. Parenteral vaccination of cattle and dogs against rabies does occur in Turkey, particularly in response to local outbreaks of disease in dogs and in recent years, wildlife outbreaks [11]. These data may be informative for rabies control strategies in other countries with domestic or wild animal reservoirs, and comparable farming systems, as well as in the design of compensation schemes for livestock losses from rabies.

\section{MATERIAL AND METHODS}

Data were analysed for the seven regions into which Turkey is divided (Fig. 1): Aegean, Black Sea, Central Anatolia, Eastern Anatolia, Marmara, Mediterranean and Southeast Anatolia. The total area covered by each of these regions varied from $59176 \mathrm{~km}^{2}$ (Southeast Anatolia) to $165436 \mathrm{~km}^{2}$ (Eastern Anatolia) (Fig. 1). These regions have been clearly delineated by geographical and climatological features. Data at the provincial level was sometimes limited to very small numbers, preventing meaningful analysis. Hence, data interpretation was considered more informative at the regional instead of at the provincial level. The total number of cattle present in each region during the period of study is given in Table 1 .

Data has been collected in Turkey per province on an annual basis from 2008 to 2011 on the number of samples submitted for diagnosis of rabies cases, the number of rabies-positive cases (including cattle) and the number of cattle vaccinated against rabies. As the number of livestock species other than cattle is only available for the whole country, the analysis was restricted to cattle. These data were made available to the Ministry of Food, Agriculture and Livestock (General Directorate of Food and Control) through the Provincial Veterinary Authorities and Rabies Diagnostic Laboratories. Rabies data presented here originates from the eight rabies diagnostic laboratories in the country. For routine diagnosis, the fluorescent antibody test (FAT) was used and in the case of human contact the FAT and the mouse inoculation test were used. Both tests were performed following WHO and OIE recommended protocols [12]. 
Table 1. Data for the number of cattle and cattle density (cattlelkm $\left.{ }^{2}\right)$ per region for the period 2008-2011 in Turkey

\begin{tabular}{|c|c|c|c|c|c|c|c|c|c|}
\hline \multirow[b]{2}{*}{ Region } & \multirow[b]{2}{*}{ Area $\left(\mathrm{km}^{2}\right)$} & \multicolumn{2}{|l|}{2008} & \multicolumn{2}{|l|}{2009} & \multicolumn{2}{|l|}{2010} & \multicolumn{2}{|l|}{2011} \\
\hline & & $n$ & Density & $n$ & Density & $n$ & Density & $n$ & Density \\
\hline Aegean & 93139 & 2084762 & $22 \cdot 38$ & 2113357 & $22 \cdot 69$ & 2239719 & $24 \cdot 05$ & 2410132 & $25 \cdot 88$ \\
\hline Black Sea & 143537 & 2032696 & $14 \cdot 16$ & 1943477 & $13 \cdot 54$ & 1998836 & 13.93 & 2109559 & $14 \cdot 70$ \\
\hline Central Anatolia & 163057 & 1889972 & $11 \cdot 59$ & 1863745 & $11 \cdot 43$ & 2057747 & $12 \cdot 62$ & 2256782 & 13.84 \\
\hline Eastern Anatolia & 165436 & 2327757 & $14 \cdot 07$ & 2292357 & $13 \cdot 86$ & 2378584 & $14 \cdot 38$ & 2645242 & 15.99 \\
\hline Marmara & 67306 & 996077 & $14 \cdot 80$ & 1049169 & $15 \cdot 59$ & 1087443 & $16 \cdot 16$ & 1186065 & $17 \cdot 62$ \\
\hline Mediterranean & 122927 & 871597 & $7 \cdot 09$ & 905004 & $7 \cdot 36$ & 945131 & $7 \cdot 69$ & 1035539 & $8 \cdot 42$ \\
\hline Southeast Anatolia & 59176 & 657081 & $11 \cdot 10$ & 644356 & $10 \cdot 89$ & 746976 & $12 \cdot 62$ & 840650 & $14 \cdot 21$ \\
\hline Total & 814578 & 10859942 & $13 \cdot 33$ & 10811465 & $13 \cdot 27$ & 11454436 & $14 \cdot 06$ & 12483969 & $15 \cdot 33$ \\
\hline
\end{tabular}

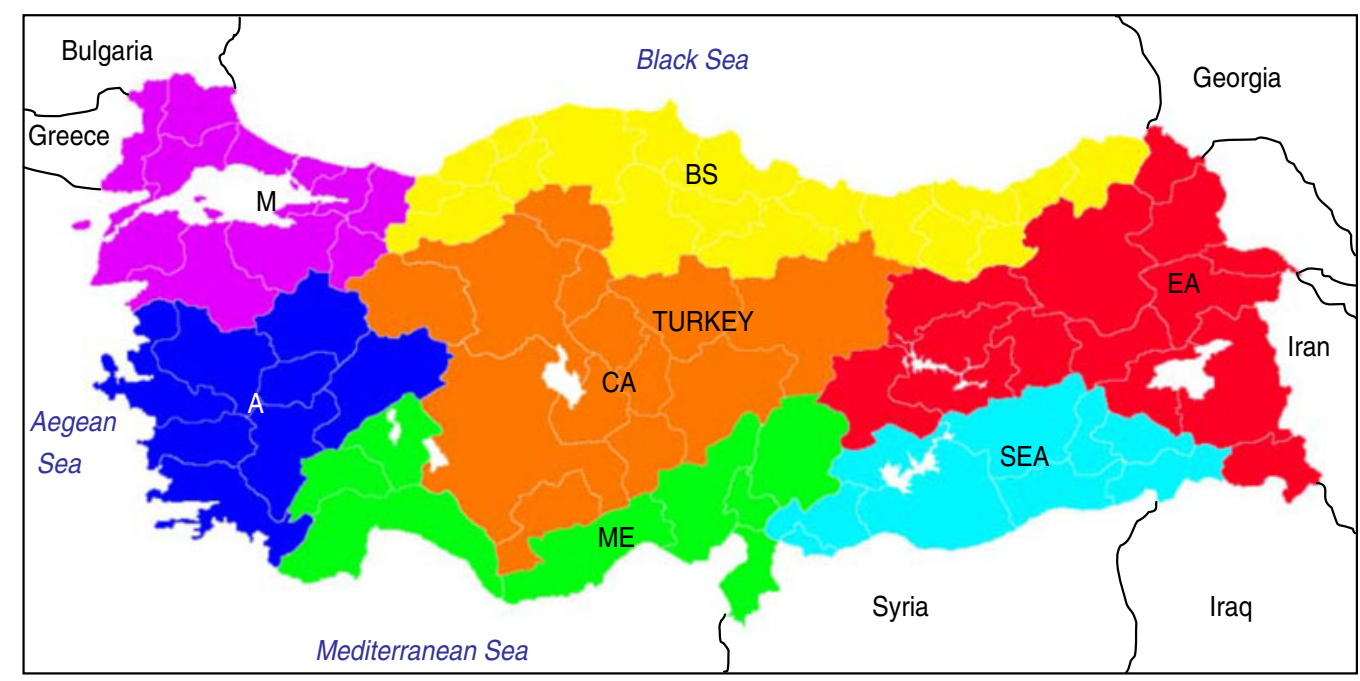

Fig. 1 [colour online]. Map of Turkey showing the different geographical regions in the study. A, Aegean region; BS, Black Sea region; CA, Central Anatolia region; EA, East Anatolia region; M, Marmara region; ME, Mediterranean region; SEA, Southeast Anatolia region. Neighbouring countries and major seas are indicated.

Generalized linear models (GLMs) were used to investigate relationships between reported incidence of bovine rabies and wildlife or dog-mediated rabies. The influence of other extrinsic factors such as region, year and surveillance effort were also investigated using GLMs. Different model error structures (Poisson and negative binomial) were compared using Akaike's Information Criterion (AIC), and the best-fitting models were chosen using the likelihood ratio test. These analyses were performed using the $\mathrm{R}$ statistical programming language [13].

The economic burden of rabies due to livestock losses in Turkey was estimated from livestock prices sourced from the Turkish Statistical Institute (http:// www.turkstat.gov.tr/PreHaberBultenleri.do?id=10843). These were converted using the purchasing power parity (PPP) rate for Turkish lira in 2010/2011
[1.132 per current international dollar (I\$)] from the World Economic Outlook database of the International Monetary Fund (www.imf.org/external/pubs/ $\mathrm{ft} /$ weo/2012/02/weodata/index.aspx). These extrapolations were discussed in relation to surveillance and compensation policies in the country.

\section{RESULTS}

During the period 2008-2011, $340[38 \cdot 6 \%, 95 \%$ confidence interval (CI) 35.9-41.4] of 881 submitted cattle specimens were diagnosed rabies positive (Table 2). Rabies submissions for cattle represented 22\% (95\% CI 20.9-23.1) of all animals submitted for rabies diagnosis; ranging from $15 \cdot 6 \%(95 \%$ CI $13.9-17 \cdot 5)$ in 2008 to $32 \cdot 8 \%(95 \%$ CI $30 \cdot 2-35 \cdot 4)$ in 2011 . The main regions reporting rabid cattle were the Aegean region 
Table 2. Number of rabies-positive cattle submitted for rabies diagnosis per region during 2008-2011

\begin{tabular}{|c|c|c|c|c|c|c|c|c|c|c|}
\hline \multirow[b]{2}{*}{ Region } & \multicolumn{2}{|l|}{2008} & \multicolumn{2}{|l|}{2009} & \multicolumn{2}{|l|}{2010} & \multicolumn{2}{|l|}{2011} & \multicolumn{2}{|l|}{ Total } \\
\hline & $\begin{array}{l}\text { No. (rabies } \\
\text { pos./total } \\
\text { submitted) }\end{array}$ & $\%$ & $\begin{array}{l}\text { No. (rabies } \\
\text { pos./total } \\
\text { submitted) }\end{array}$ & $\%$ & $\begin{array}{l}\text { No. (rabies } \\
\text { pos./total } \\
\text { submitted) }\end{array}$ & $\%$ & $\begin{array}{l}\text { No. (rabies } \\
\text { pos./total } \\
\text { submitted) }\end{array}$ & $\%$ & $\begin{array}{l}\text { No. (rabies } \\
\text { pos./total } \\
\text { submitted) }\end{array}$ & $\%$ \\
\hline Aegean & $32 / 99$ & $32 \cdot 3$ & $11 / 81$ & $13 \cdot 6$ & $10 / 126$ & $7 \cdot 9$ & $34 / 183$ & $18 \cdot 6$ & $87 / 489$ & $17 \cdot 8$ \\
\hline Black Sea & $2 / 9$ & $22 \cdot 2$ & $0 / 2$ & 0 & $0 / 3$ & 0 & $6 / 11$ & $54 \cdot 5$ & $8 / 25$ & 32 \\
\hline Central Anatolia & $0 / 0$ & 0 & $3 / 14$ & $21 \cdot 4$ & $0 / 2$ & 0 & $10 / 10$ & 100 & $13 / 26$ & 50 \\
\hline Eastern Anatolia & $25 / 31$ & $80 \cdot 6$ & $16 / 19$ & $84 \cdot 2$ & $8 / 9$ & 88.9 & $11 / 13$ & $84 \cdot 6$ & $60 / 72$ & $83 \cdot 3$ \\
\hline Marmara & $3 / 5$ & 60 & $3 / 16$ & $18 \cdot 8$ & $14 / 18$ & $77 \cdot 8$ & $21 / 43$ & $48 \cdot 8$ & $41 / 82$ & 50 \\
\hline Mediterranean & $17 / 22$ & $77 \cdot 3$ & $35 / 46$ & $76 \cdot 1$ & $6 / 23$ & $26 \cdot 1$ & $10 / 19$ & $52 \cdot 6$ & $68 / 110$ & $61 \cdot 8$ \\
\hline Southeast Anatolia & $14 / 16$ & $87 \cdot 5$ & $18 / 19$ & $94 \cdot 7$ & $14 / 19$ & $73 \cdot 7$ & $17 / 23$ & $73 \cdot 9$ & $63 / 77$ & $81 \cdot 8$ \\
\hline Total & $93 / 182$ & $51 \cdot 1$ & $86 / 197$ & $43 \cdot 6$ & $52 / 200$ & 26 & $109 / 302$ & $36 \cdot 1$ & $340 / 881$ & $38 \cdot 6$ \\
\hline
\end{tabular}

Table 3. Number or rabies cases reported in cattle, dogs and wildife per region during 2008-2011

\begin{tabular}{|c|c|c|c|c|c|c|c|c|c|c|c|c|}
\hline \multirow[b]{2}{*}{ Region } & \multicolumn{3}{|l|}{2008} & \multicolumn{3}{|l|}{2009} & \multicolumn{3}{|l|}{2010} & \multicolumn{3}{|l|}{2011} \\
\hline & Cattle & Dogs & Wildlife & Cattle & Dogs & Wildlife & Cattle & Dogs & Wildlife & Cattle & Dogs & Wildlife \\
\hline Aegean & 32 & 19 & 33 & 11 & 5 & 3 & 10 & 5 & 8 & 34 & 6 & 16 \\
\hline Black Sea & 2 & 2 & 7 & - & 11 & 2 & - & 6 & - & 6 & 3 & 2 \\
\hline Central Anatolia & - & 1 & - & 3 & 7 & - & - & - & - & 10 & 4 & 9 \\
\hline Eastern Anatolia & 25 & 44 & 2 & 16 & 34 & 10 & 8 & 24 & 4 & 11 & 38 & 6 \\
\hline Marmara & 3 & 31 & 3 & 3 & 25 & - & 14 & 15 & 3 & 21 & 10 & 11 \\
\hline Mediterranean & 17 & 33 & 1 & 35 & 25 & 5 & 6 & 14 & - & 10 & 11 & 1 \\
\hline Southeast Anatolia & 14 & 23 & 4 & 18 & 22 & 1 & 14 & 12 & - & 17 & 27 & 4 \\
\hline Total & 93 & 153 & 50 & 86 & 22 & 21 & 52 & 76 & 15 & 109 & 99 & 49 \\
\hline
\end{tabular}

and the Marmara region. The highest incidence of rabies in cattle was observed in the Aegean region in every year tested, with a total of 87 rabid cattle reported in this region during the study period. The lowest incidence was in the Black Sea region with eight cases reported between 2008 and 2011. Over the 4 years of the study, differences in cases detected were not statistically significant, with no consistent trend observed across the country as a whole. However, regional differences were apparent, with cases detected in the Aegean region, differing significantly from the Black Sea region and Central Anatolia. The Aegean region saw a reduction in cattle cases between 2008 and 2009, which reversed between 2010 and 2011. The Marmara region saw a steady increase over the last 3 years of observation, whereas the Mediterranean region saw a peak of 35 positive cases in 2009 , the highest observed in any year from any region, which then declined to single figures in the following years.

To understand bovine rabies epidemiology in the different regions of Turkey, it was necessary to examine rabies in reservoir hosts, specifically dogs and wildlife (Table 3). During the study period samples were most commonly submitted from domestic dogs (48.3\%, 95\% CI 47.0-49.6) and accounted for most rabies cases reported $(46 \cdot 8 \%, 95 \%$ CI $44 \cdot 2-49 \cdot 5)$. Cases of rabies in wildlife were also reported from most regions throughout the study. Although the general pattern in rabies cases in dogs, wildlife and cattle were similar for the country as a whole (declines from 2008-2010, followed by an increase in 2011), they varied by region. In 2008, rabies-positive animals were dominated by dogs, with the exception of the Aegean region where both cattle and wildlife cases exceeded the number of rabid dogs (Table 3). The Black Sea and Central Anatolian regions reported a relatively low incidence of rabies in comparison with the rest of the country with only two and one cases of rabid dogs, respectively. By 2011 the number of rabid cattle reported in Turkey had risen to 109 from just 52 in 2010 and exceeded the number of rabid dogs reported.

The best-fitting models that described the variation in cattle rabies cases all had a negative binomial error 
Table 4. Number of cattle vaccinated and vaccination coverage in cattle for the different regions during 2008-2011

\begin{tabular}{|c|c|c|c|c|c|c|c|c|}
\hline \multirow[b]{2}{*}{ Region } & \multicolumn{2}{|l|}{2008} & \multicolumn{2}{|l|}{2009} & \multicolumn{2}{|l|}{2010} & \multicolumn{2}{|l|}{2011} \\
\hline & $n$ & Coverage $(\%)$ & $n$ & Coverage $(\%)$ & $n$ & Coverage $(\%)$ & $n$ & Coverage $(\%)$ \\
\hline Aegean & 633356 & $30 \cdot 4$ & 744165 & $35 \cdot 2$ & 34034 & $1 \cdot 5$ & 53599 & $2 \cdot 2$ \\
\hline Black Sea & 6828 & $0 \cdot 3$ & 8157 & $0 \cdot 4$ & 56 & $0 \cdot 0$ & 443 & $0 \cdot 0$ \\
\hline Central Anatolia & - & - & 2324 & $0 \cdot 1$ & - & - & 10906 & $0 \cdot 5$ \\
\hline Eastern Anatolia & 2803 & $0 \cdot 1$ & 5710 & $0 \cdot 2$ & 1329 & $0 \cdot 1$ & 5612 & $0 \cdot 2$ \\
\hline Marmara & 2403 & $0 \cdot 2$ & 2475 & $0 \cdot 2$ & 17900 & $1 \cdot 6$ & 34255 & $2 \cdot 9$ \\
\hline Mediterranean & 16750 & 1.9 & 49778 & $5 \cdot 5$ & 20802 & $2 \cdot 2$ & 37056 & $3 \cdot 6$ \\
\hline Southeast Anatolia & 1960 & $0 \cdot 3$ & 2111 & $0 \cdot 3$ & 2334 & $0 \cdot 3$ & 1953 & $0 \cdot 2$ \\
\hline Total & 664100 & $6 \cdot 1$ & 814720 & $7 \cdot 5$ & 76455 & $0 \cdot 7$ & 143824 & $1 \cdot 2$ \\
\hline
\end{tabular}

structure rather than a Poisson error structure, indicating overdispersion in the data, i.e. considerable variability. Significant positive relationships between annual bovine rabies cases in each region and rabies cases in both wildlife and in dogs were detected. The relationship between bovine cases and cases in both dogs and wildlife differed in the Aegean region compared to the rest of the country, with more cattle cases detected per rabid dog in the Aegean region. After excluding data from the Aegean region, dog cases in each region each year were found to be a better predictor of bovine cases than wildlife cases were (Fig. 2). Rabies cases in dogs and in wildlife reported annually in each region were not correlated with each other. Cases in wildlife were positively correlated with both regional cattle numbers and cattle density, while cases in dogs were not.

Cattle density was highest in the Aegean region and lowest in the Mediterranean region (Table 1). However, numbers and density of cattle increased in all the regions during the study period rising from a national average of $13.3 \mathrm{cattle} / \mathrm{km}^{2}$ in 2008 to 15.3 cattle $/ \mathrm{km}^{2}$ in 2011 . Over the 3 years 1.7 million cattle were vaccinated, resulting in a very low vaccination coverage at the national level $(<10 \%$, Table 4$)$. The only exception to this was in the Aegean region where over $30 \%$ of cattle were vaccinated in 2008 and 2009. During these years $95 \cdot 4 \%(95 \%$ CI $95 \cdot 33-$ $95 \cdot 41)$ and $91 \cdot 3 \%$ (95\% CI 91.29-91.39) of all vaccinated cattle in Turkey originated from this region. However, by the end of the study, coverage was negligible in almost all regions $(<5 \%)$.

No correlation was found between the number of rabid cattle and cattle density or total number of cattle. However, rabies incidence and surveillance effort (number of cattle submitted/100000 animals) showed large regional differences (Table 5). The highest level

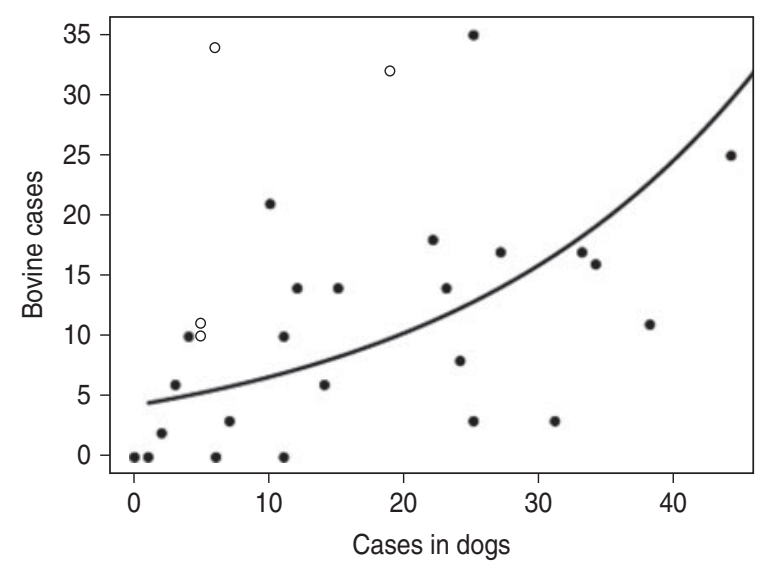

Fig. 2. The relationship between rabies cases in domestic dogs and in cattle reported annually from each region. Although this relationship was described well by a general linear model with negative binomial errors (-), the model fit improved with the removal of data from the Aegean region (O).

of surveillance effort was usually observed in the Aegean region with the exception of 2009 where the highest surveillance effort was observed in the Mediterranean region. The highest rabies incidence (rabies-positive cases $/ 100000$ cows) of $5 \cdot 1$ was also observed in the Mediterranean region in 2009, which declined over the following 2 years to $2 \cdot 02$.

The density, surveillance effort and rabies incidence for different livestock species (cattle, equids, sheep, goats) for the whole country are given in Table 6 . Adjusting for PPP, the average price for domestic cattle in Turkey was estimated at around I $\$ 2800$ per head in 2010/11. Cross-breeds and cultural breeds were valued more highly, while calves were of lesser value. Extrapolating from confirmed bovine rabies cases would suggest that livestock losses amount to around I\$240000 annually (ranging from I\$146000 
Table 5. Surveillance effort (submissions/100000 cows) and rabies incidence (cases/100000 cows) for the different regions during 2008-2011

\begin{tabular}{|c|c|c|c|c|c|c|c|c|}
\hline \multirow[b]{2}{*}{ Region } & \multicolumn{2}{|l|}{2008} & \multicolumn{2}{|l|}{2009} & \multicolumn{2}{|l|}{2010} & \multicolumn{2}{|l|}{2011} \\
\hline & Surveillance & Rabies & Surveillance & Rabies & Surveillance & Rabies & Surveillance & Rabies \\
\hline Aegean & $4 \cdot 7$ & $1 \cdot 53$ & $3 \cdot 8$ & 0.52 & $5 \cdot 6$ & $0 \cdot 45$ & $7 \cdot 6$ & $1 \cdot 41$ \\
\hline Black Sea & $0 \cdot 4$ & $0 \cdot 10$ & $0 \cdot 1$ & - & $0 \cdot 2$ & - & 0.5 & $0 \cdot 28$ \\
\hline Central Anatolia & - & - & $0 \cdot 8$ & $0 \cdot 16$ & $0 \cdot 1$ & - & $0 \cdot 4$ & $0 \cdot 44$ \\
\hline Eastern Anatolia & $1 \cdot 3$ & $1 \cdot 07$ & $0 \cdot 8$ & $0 \cdot 70$ & $0 \cdot 4$ & $0 \cdot 34$ & 0.5 & $0 \cdot 42$ \\
\hline Marmara & 0.5 & $0 \cdot 30$ & 1.5 & $0 \cdot 29$ & $1 \cdot 7$ & $1 \cdot 29$ & $3 \cdot 6$ & $1 \cdot 77$ \\
\hline Mediterranean & $2 \cdot 5$ & 1.95 & $5 \cdot 1$ & $3 \cdot 87$ & $2 \cdot 4$ & $0 \cdot 63$ & $1 \cdot 8$ & $0 \cdot 97$ \\
\hline Southeast Anatolia & $2 \cdot 4$ & $2 \cdot 13$ & $2 \cdot 9$ & 2.79 & $2 \cdot 5$ & $1 \cdot 87$ & $2 \cdot 7$ & $2 \cdot 02$ \\
\hline Total & $1 \cdot 7$ & $0 \cdot 86$ & $1 \cdot 8$ & $0 \cdot 80$ & $1 \cdot 7$ & $0 \cdot 45$ & $2 \cdot 4$ & $0 \cdot 87$ \\
\hline
\end{tabular}

to I $\$ 306000$ between 2008 and 2011). However, from January until August 2012, the Turkish government provided compensation of almost 338000 Turkish lira (I\$411000) to farmers as a result of livestock losses to rabies. Confirmed bovine cases probably represent only a relatively small proportion of total bovine rabies cases. This proportion may vary according to surveillance levels and policies for compensation. For example, laboratory confirmation of at least one animal may be needed to compensate for an outbreak that may have killed many animals, or compensation may be on the basis of clinical signs and/or epidemiological history alone.

In general, the numbers of rabies cases detected increased as surveillance effort increased (Table 5). The economic value of the different livestock species appears to play an important role in surveillance intensity and, consequently, detected rabies incidence. The highest rabies incidence was recorded in equids (horses and donkeys) although the number of animals is relatively low. Meanwhile, rabies cases in the most abundant livestock species, sheep, with relatively low economic value are rare due to the low number of animals submitted.

\section{DISCUSSION}

Rabies in cattle has a direct economic impact on the livestock industry and represents a public health threat in rabies-endemic areas. Assessing the burden of rabies in cattle is important for the planning of costeffective control strategies. Turkey has a welldeveloped surveillance system for diagnosing rabies and has made repeated attempts to eliminate the disease [12]. However, rabies persists in Turkey in the form of both dog-mediated and fox-mediated rabies.
Wildlife rabies appears to represent a greater risk to cattle than dog-mediated rabies in Turkey, where dog rabies remains more of a problem in (semi-) urban areas. Yet recent spread of fox-mediated rabies from the Aegean region into neighbouring regions could result in substantially greater economic losses from rabies.

On average 85 rabies cases in cattle were reported annually from Turkey between 2008 and 2011. In the whole of Europe between 2001 and 2010 on average 958 rabid cows were reported annually [range 539 (2009) to 1520 (2002)]. So of the total number of bovine rabies cases in Europe, $8.9 \%$ originated from Turkey. Most of the remaining cases were reported from Russia, Belarus and Ukraine (source: Rabies Bulletin Europe), countries where wildlife rabies dominates the epidemiology of the disease. In the USA, where rabies cases in cattle are wildlife transmitted, the incidence in cattle fluctuated annually between 57 (2007) and 116 (2002) during 2001-2010 $[14,15]$. Confirmed livestock cases in Turkey amount to around I\$240000; however. actual losses could be considerably higher, depending upon whether most cattle deaths due to rabies are submitted for laboratory diagnosis.

There were clear spatial and temporal differences in the reported rabies incidence in cattle in areas affected by dog rabies, with a range from 0 to 3.87 cases/ 100000 head of cattle. The highest incidence $(3 \cdot 87 /$ 100000 ) was observed for the Mediterranean region in 2009. At the peak of the rabies outbreak, 236 rabid bovines were reported from the Aegean region in 2002 [16], resulting in a conservative estimate of 23.6 rabies cases $/ 100000$ head of cattle. Economic losses from rabies incidence at this time would have been around I\$1.5 million in the Aegean region, 


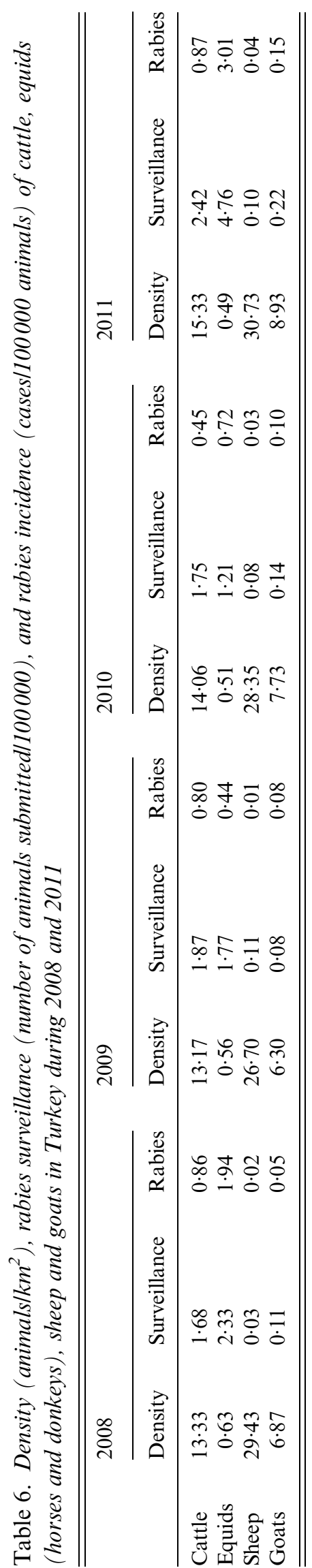

demonstrating how uncontrolled endemic rabies can lead to substantial costs.

Cattle submissions from Turkey were dominated by those from the Aegean region. The high number of cattle submitted for rabies diagnosis in this region was unrelated to the number of cattle, although cattle density in this region is the highest for the whole country. A fox rabies outbreak in the region began in the late 1990s following sustained spillover of infection from dogs to foxes [16]. Subsequent intensified control programmes, including oral vaccination targeting foxes, enhanced surveillance efforts and mass vaccination campaigns of cattle were implemented. The incidence of rabies in livestock appears to be influenced by the reservoir host, with varying patterns across the country. Incidence in the Aegean region was higher than other regions, where dog-mediated rabies predominates (Fig 2). This reflects the excellent infrastructure and access to veterinary services in this region. During three annual oral vaccination campaigns in the most affected area of the Aegean region between 2008 and 2010, fox rabies was eliminated. This is reflected by the decline in the number of rabies cases reported from this region between 2009 and 2010, but with resurgence in 2011. Unfortunately, fox rabies had already spread beyond the vaccination area in the Aegean region and re-emerged in the vaccination area in 2011. Furthermore, fox rabies reached the Marmara region and Central Anatolian region in 2010 and 2011, respectively [17]. Rabies incidence in the Central Anatolian region during the past decade has always been low and the re-emergence of rabies in wildlife could have grave consequences for the rabies situation here. In the first half of 2012, 13 cases of fox rabies were reported from this region. The emergence of fox rabies is the likely cause of the appearance of rabies in cattle in this region in 2011. The rabies situation in the Black Sea, Mediterranean and Southeast Anatolian regions is dominated by dog-mediated transmission with suspected self-limiting spillover infections in wildlife species such as foxes and golden jackals (Canis aureus). However, the situation for Eastern Anatolia is less clear; here rabies cases in dogs clearly dominate but surveillance data of wildlife is so limited, that an independently sustained infection cycle in wildlife cannot be excluded.

Wildlife rabies in Turkey has been a cause for increases in the number of rabies cases in cattle. In contrast, domestic dogs are the major source of livestock rabies in Tanzania and Bhutan [8-10]. 
Similarities may exist with certain regions of Turkey and in Southern Africa, where dog-mediated rabies is also a major source of transmission to livestock $[18,19]$. However, there is almost no reliable data available on rabies incidence in cattle for many countries, especially in Africa and Asia. Limited data on submissions of cattle specimens to diagnostic laboratories indicated an incidence of $0 \cdot 5-2$ rabies deaths/ 100000 head of cattle for some countries [7]. However, this was considered a gross underestimation, with incidence in cattle estimated to be 5 animals/ 100000 head of cattle for Africa and Asia [7]. The reasons for underestimation are numerous. For example, in many countries in Africa and Asia surveillance systems are inadequate or are entirely lacking [20]. Furthermore, the submission of samples, especially in the case of livestock, is problematic due to the size of animals, an absence of a cold chain and the cost of transportation to the diagnostic laboratory. Moreover, rabies in cattle could be attributed to other disease-causing agents. For example in Africa, common causes of disease in cattle include heartwater disease or cowdriosis, caused by Ehrlichia ruminantium [21] and East Coast Fever or corridor disease, caused by Theileria parva [22]. Numbers of confirmed bovine cases from Turkey are typically around 1/100000 animals, indicating that incidence is likely to be at least 1 case/100000 animals and may be more than 5/100000 animals. The degree of underreporting in Turkey may be more influenced by incentives to submit samples. In the western part of Turkey many farmers have insurance policies and therefore, every animal suspected of being infected with rabies will be submitted, especially valuable species like cattle. In the less affluent eastern part of the country, most farmers do not have insurance and subsequently famers will be less likely to submit livestock for rabies diagnosis. Not only because there are no direct benefits (compensation) of reporting but also to avoid possible negative consequences such as the implementation of quarantine measures, trade and movement restrictions and destruction of the affected herd. All of these can cause considerable financial losses for the farmer involved. Thus, without some kind of compensation, there are in many cases little or no incentives for the owner to submit or report a case.

Since 2012, the Turkish government initiated a compensation scheme for farmers. However, it is too early to assess the impact of this scheme on the willingness to submit animals for rabies diagnosis. Such compensation schemes will unfortunately not be feasible for most developing countries in Asia and Africa. Such schemes require a pre-existing ownership recording system and sufficient financial resources to provide (timely) compensation [23]. In addition, compensation schemes are susceptible to misuse, especially when not only submitted and rabies-affected cattle are compensated but also livestock that are culled during an outbreak.

The only region for which there is some reliable data on bovine rabies is from Latin America. It is estimated that over one third of the world's cattle is raised in Latin America and despite the control of dogmediated rabies transmission throughout the whole region, transmission to livestock occurs from the common vampire bat. The availability of efficacious and safe tissue-culture vaccine and introduction of vampire bat management schemes has caused the number of cases in countries affected by vampiretransmitted bovine rabies to decrease considerably. For example, in Brazil the number of cases dropped from an estimated 200000 in 1968 to 1321 in 2002 [24, 25]. Estimates of rabies incidence and vaccination coverage for Brazil in 1999 were 1.65/100000 rabid cows and 10885/100000 vaccinated cows, respectively [26]. Both estimates are higher than those estimated for Turkey between 2008 and 2011. The higher vaccination coverage in the Aegean region for 2008 and 2009 was a result of mass vaccination campaigns organized by the Ministry of Food, Agriculture and Livestock (formerly Ministry of Agricultural and Rural Affairs) and co-financed with the support of the European Union.

It can be concluded that in Turkey, spatial differences in bovine rabies occurs based on the reservoir host (domestic dog or fox) involved, but spatial biases in surveillance intensity are clearly also present. Many possible reasons for underreporting have been identified, including among others: lack of awareness, lack of personnel, logistic difficulties, lack of diagnostic equipment and capacity, lack of compensation and lack of feedback [23]. However, limitations present in other countries related to veterinary staff, laboratory diagnostic facilities and communication infrastructures are not a limiting factor for rabies surveillance in Turkey. In contrast, the effect of compensation schemes seems to play an important role as an incentive. Confirmed bovine cases indicating economic losses in Turkey are not substantial, but these costs could escalate rapidly if control measures are not put in place to prevent the further spread of fox-mediated rabies. 


\section{ACKNOWLEDGEMENTS}

The contributions of H.Ü., C.F., O.A., T.M. were part of an OIE-funded laboratory twinning project on rabies between FLI and EVCCRI (file ref.: $\mathrm{GKB} / \mathrm{KH} / 2009 / 22)$. KH was supported by the Wellcome Trust (095787/Z/11/Z) and the Medical Research Council (G0901135). N.J. and A.R.F. are funded by Defra grant SV3500. The authors acknowledge the Partners for Rabies Prevention for providing the impetus for this research.

\section{DECLARATION OF INTEREST}

A. R. Fooks is an associate editor of Epidemiology and Infection.

\section{REFERENCES}

1. Nel LH, Markotter W. Lyssaviruses. Critical Reviews in Microbiology 2007; 33: 301-324.

2. Haydon DT, et al. Identifying reservoirs of infection: a conceptual and practical challenge. Emerging Infectious Diseases, 2002; 8: 1467-1473.

3. Delpietro HA, et al. Observations of sylvatic rabies in northern Argentina during outbreaks of paralytic cattle rabies transmitted by vampire bats (Desmodus rotundus). Journal of Wildlife Diseases 2009; 45: 11691173.

4. Tang HB, et al. Complete genome sequence of a rabies virus isolate from cattle in Guangzi, southern China. Genome Announcements 2013; 1: e00137-12.

5. Lojkić I, et al. Clinical rabies in cattle imported into Croatia. Veterinary Record 2013; 172: 22-23.

6. DuVerney TS, et al. The first laboratory-confirmed rabid pig in Marlyand, 2003. Zoonoses and Public Health 2008; 55: 431-435.

7. Knobel DL, et al. Re-evaluating the burden of rabies in Africa and Asia. Bulletin of the World Health Organisation 2005; 83: 360-368.

8. Tenzin, et al. Reemergence of rabies in Chhukha District, Bhutan, 2008. Emerging Infectious Diseases 2010; 16: $1925-1930$.

9. Tenzin, et al. Re-emergence of rabies in dogs and other domestic animals in eastern Bhutan, 2005-2007. Epidemiology and Infection 2011; 139: 220-225.

10. Lembo T, et al. Exploring reservoir dynamics: a case study of rabies in the Serengeti ecosystem. Journal of Applied Ecology 2008; 45: 1246-1257.
11. Johnson $\mathbf{N}$, et al. Rabies emergence among foxes in Turkey. Journal of Wildlife Diseases 2003; 39: 262-270.

12. Johnson $\mathbf{N}$, et al. Rabies epidemiology and control in Turkey: past and present. Epidemiology and Infection 2010; 138: 305-312.

13. R Development Core Team. R: A language and environment for statistical computing. Vienna, Austria: R Foundation for Statistical Computing, 2009.

14. Krebs JW, et al. Rabies surveillance in the United States during 2002. Journal of the American Veterinary Medical Association 2003; 223: 1736-1748.

15. Blanton JD, et al. Rabies surveillance in the United States during 2007. Journal of the American Veterinary Medical Association 2008; 233: 884-897.

16. Vos A, et al. Rabies in foxes, Aegean region, Turkey. Emerging Infectious Diseases 2009; 15: 1620-1622.

17. Ün $\mathbf{H}$, et al. Oral vaccination of foxes against rabies in Turkey between 2008 and 2010. Berliner und Muenchener Tieraerztliche Wochenschrift 2012; 125: 203-208.

18. Swanepoel R, et al. Rabies in southern Africa. Onderstepoort Journal of Veterinary Research 1993; 60: $325-346$.

19. Rhodes CJ, et al. Rabies in Zimbabwe: reservoir dogs and the implications for disease control. Philosophical Transactions of the Royal Society London, Series B: Biological Sciences 1998; 353: 999-1010.

20. Banyard AC, et al. Control and prevention of canine rabies: The need for building laboratory-based surveillance capacity. Antiviral Research 2013; 98: 357-64.

21. Frutos R, et al. Ehrlichia ruminatium: genomic and evolutionary features. Trends in Parasitology 2007; 23: 414419.

22. Gachohi J, et al. Epidemiology of East Coast fever (Theileria parva infection) in Kenya: past, present and future. Parasites and Vectors 2012; 5:194.

23. Halliday $\mathbf{J}$, et al. Bringing together emerging and endemic zoonoses surveillance: shared challenges and a common solution. Philosophical Transactions of the Royal Society London, Series B: Biological Sciences 2012; 367: 2872-2880.

24. Acha NP. Epidemiology of bovine paralytic rabies transmitted by Chiroptera. Boletín de la Oficina Sanitaria Panamericana 1968; 64: 411-430.

25. Belotto A, et al. Overview of rabies in the Americas. Virus Research 2005; 111: 5-12.

26. Mayen F. Haematophagous bats in Brazil, their role in rabies transmission, impact on public health, livestock industry and alternatives to an indiscriminate reduction of bat population. Journal of Veterinary Medicine $B$ 2003; 50: 469-472. 